\title{
Micellar Effect On Dephosphorylation Of Bis-4-Chloro-3,5- Dimethylphenylphosphate Ester By Peroxy Anions
}

\author{
Anuradha Teotia ${ }^{1}$, Dr. M.S. Baghel ${ }^{2}$

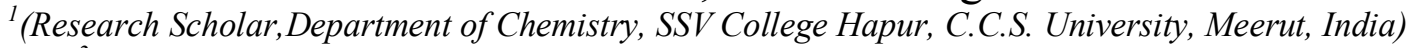 \\ ${ }^{2}$ (Faculty, Department of Chemistry, SSV College Hapur, C.C.S. University, Meerut, India)
}

\begin{abstract}
The rate enhancement depends on the hydrophobicity of the nucleophile. The micellar catalyzed reaction between bis-4-chloro-3,5-dimethylphenylphosphate ester and hydroxide or hydroperoxide anions has been examined in buffered medium ( $\mathrm{pH}$ 8-10). First order rate constant $\left(K_{\psi}\right)$ for the reaction of hydroxide ion with bis-4-CDMPP go through maxima with the increasing concentration of cetyltrimethylammoniumbromide (CTABr). Micelles of CTABr very effective catalyst to the reactions of phosphate diesters. Rate constants measured with $\mathrm{OH}_{2}^{-}$ions are approximately twice and thrice than that of $\mathrm{OH}$ ions in presence of CTABr.
\end{abstract}

Keywords: CTABr , Micelles, Miceller Catalyses, 4-CDMPP.

\section{Introduction}

Micellar catalysis of phosphate diesters has been reported by Bunton et. al., and Bengunov et. al., ${ }^{[1-3]}$, but little attention has been devoted to the micellar catalysis of hydroperoxy anion $\left(\mathrm{OH}_{2}{ }^{-}\right)$assisted hydrolysis. Bunton and Mhala ${ }^{[4]}$ recently reported that micelles of $\mathrm{CTABr}$ catalyse the reaction of hydrolysis by adding $\mathrm{OH}_{2}{ }^{-}$ion which interested us to investigate the micellar catalysed hydrolysis of 4-CDMPP diester with $\mathrm{OH}^{-}$and $\mathrm{OH}_{2}^{-}$ions.

The effect of ionic strength ${ }^{[5]}$ was studied by carrying out kinetic runs at different ionic strengths. In most of the micellar catalyzed reactions, the substrate is incorporated into the micellar pseudophase and is attacked by an external reagent or decomposes spontaneously ${ }^{[6]}$. On taking into the consideration, the above mentioned observations, following scheme has been suggested for the mechanism of the hydrolysis of 4$\mathrm{CDMPP}$ and $\mathrm{OH}^{-}$ions.

Scheme:<smiles>CC(C)OP(=O)(OC(C)(C)C)OC(C)(C)C</smiles>

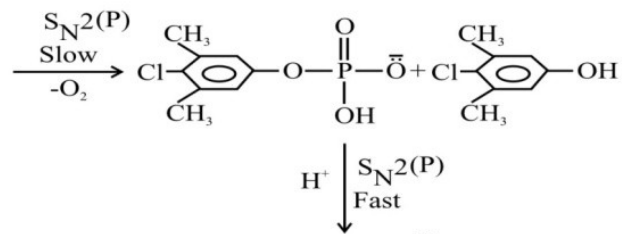

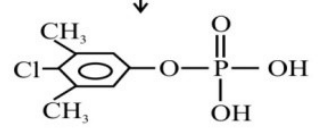

\subsection{Material-}

\section{Experimental}

Diester of 4-Chloro-3, 5-dimethylphenylphosphate (4-CDMPP) is synthesized by the method of Auger and Dupius ${ }^{[7]}$ and recrystalysed by absolute EtOH. The compound was fully characterized by IR spectrum at different strengths of $\mathrm{OH}^{-}$ions, were used to study the rate enhancement at different $\mathrm{pH}$ (as for $\mathrm{pH} 8-3.9 \times 10^{-3}$ mol dm${ }^{-3}$, for $\mathrm{pH} 9-20.8 \times 10^{-3} \mathrm{~mol} \mathrm{dm}^{-3}$, for $\mathrm{pH} 10-43.8 \times 10^{-3}$ mole $\mathrm{dm}^{-3}$ ) with different concentrations of $\mathrm{CTABr}$ (Cetyltrimethyl ammonium bromide). The CTABr used was of analytical grade. Other reagents and surfactants used were prepared and purified by standard methods. ${ }^{[8-10]}$

\subsection{Kinetics-}

Reactions were followed by 'sistronics' spectrophotometer at absorbance $662 \mathrm{~nm}$ to obtain pseudo first order rate constants. The $\mathrm{pH}$ of the reaction mixtures were adjusted to the above given values. All the reactions were carried out at $40 \pm 0.5^{\circ} \mathrm{C}$. 


\subsection{Result and Discussion-}

Pseudo first order rate constant were determined in the aqueous medium, where a small amount of sodium hydroxide is ionized to give hydroxide ions which gave small values of rate constants without surfactant at different $\mathrm{pH}$, are given in table- 1 . The reactions of $\mathrm{OH}^{-}$and $\mathrm{OH}_{2}{ }^{-}$ions are very strongly catalysed by cationic micelles of CTABr. The rate constants have been calculated and shown in terms of concentration of $\mathrm{CTABr}$ at different $\mathrm{pH}$.

TABLE-1: Pseudo first order constants for the hydrolysis of bis-4-CDMPP $\left(5 \times 10^{-4} \mathrm{~mol} \mathrm{dm}^{-3}\right)$ at $\mathrm{pH} 9$ and $40 \pm$ $0.5^{\circ} \mathrm{C}$.

\begin{tabular}{|c|c|c|c|c|c|c|c|c|c|c|c|c|c|}
\hline \multirow[b]{2}{*}{$\begin{array}{l}\mathrm{p} \\
\mathrm{H}\end{array}$} & \multirow{2}{*}{$\begin{array}{c}103 \\
{[\mathrm{OH}-} \\
] \mathrm{mol} \\
\mathrm{dm}-3\end{array}$} & \multirow{2}{*}{$\begin{array}{c}105 \\
\text { K'w s- } \\
1\end{array}$} & \multicolumn{11}{|c|}{$105 \mathrm{~K} \psi \mathrm{s}-1$ in 103 [CTABr] mol dm-3 } \\
\hline & & & 0.2 & 0.4 & 0.6 & 0.8 & 1.0 & 1.2 & 1.4 & 1.6 & 1.8 & 2.0 & 2.2 \\
\hline 8 & 3.9 & 3.42 & 3.75 & 4.23 & 6.08 & 7.16 & 9.41 & 12.11 & 13.62 & $\begin{array}{c}16.6 \\
5\end{array}$ & 19.17 & $\begin{array}{c}11.8 \\
7\end{array}$ & 5.36 \\
\hline 9 & 20.8 & 5.23 & 6.15 & 7.13 & 8.76 & $\begin{array}{c}11.1 \\
5\end{array}$ & $\begin{array}{c}14.3 \\
1\end{array}$ & 17.83 & 21.36 & $\begin{array}{c}22.7 \\
7\end{array}$ & 29.86 & $\begin{array}{c}20.1 \\
4\end{array}$ & 9.42 \\
\hline 10 & 43.8 & 7.25 & 8.92 & $\begin{array}{c}11.3 \\
1\end{array}$ & $\begin{array}{c}14.1 \\
9\end{array}$ & $\begin{array}{c}18.3 \\
2\end{array}$ & $\begin{array}{c}22.7 \\
5\end{array}$ & 28.52 & 31.64 & $\begin{array}{c}33.5 \\
7\end{array}$ & 40.74 & $\begin{array}{c}29.1 \\
1\end{array}$ & 17.26 \\
\hline
\end{tabular}

The rate constants for the reactions of $\mathrm{OH}_{2}{ }^{-}$ions with diesters of 4-CDMPP increase sharply with the increase of [CTABr] (summarized in table 2). They rise to the maxima and then decrease steadily. This is common for bimolecular micellar catalyzed reactions.

TABLE- 2: Rate constants for reaction with $\mathrm{H}_{2} \mathrm{O}_{2}$ in presence of CTABr at pH 9 and $40 \pm 0.5^{\circ} \mathrm{C}$.

\begin{tabular}{|c|c|c|c|}
\hline \multirow{2}{*}{ S.No. } & $10^{3}[\mathrm{CTABr}] \mathrm{mol} \mathrm{dm}^{-3}$ & \multicolumn{2}{|c|}{$10^{5} \mathrm{~K}_{\psi} \mathrm{s}^{-1}$ in presence of [CTABr] } \\
\cline { 3 - 4 } & & $\mathrm{H}_{2} \mathrm{O}_{2} 0.8 \times 10^{-3} \mathrm{~mol} \mathrm{dm}^{-3}$ & $\mathrm{H}_{2} \mathrm{O}_{2} 1.2 \times 10^{-3} \mathrm{~mol} \mathrm{dm}^{-3}$ \\
\hline 1. & 0.2 & 19.24 & 29.11 \\
\hline 2. & 0.4 & 32.83 & 47.25 \\
\hline 3. & 0.6 & 43.16 & 66.85 \\
\hline 4. & 0.8 & 55.12 & 82.73 \\
\hline 5. & 1.0 & 64.79 & 96.15 \\
\hline 6. & 1.2 & 73.68 & 104.21 \\
\hline 7. & 1.4 & 78.17 & 108.77 \\
\hline 8. & 1.6 & 81.84 & 113.76 \\
\hline 9. & 1.8 & 83.37 & 114.26 \\
\hline 10. & 2.0 & 72.31 & 82.81 \\
\hline 11. & 2.2 & 55.42 & 82.27 \\
\hline
\end{tabular}

First order rate constants determined for $\mathrm{OH}^{-}$and $\mathrm{OH}_{2}{ }^{-}$assisted reactions which go through maxima at $1.6 \times 10^{-3} \mathrm{~mol} \mathrm{dm}^{-3}$ [CTABr] is $29.86 \times 10^{-5} \mathrm{~s}^{-1}$ with $20.8 \times 10^{-3} \mathrm{~mol} \mathrm{dm}^{-3} \mathrm{OH}^{-}$ions and $114.26 \times 10^{-5} \mathrm{~s}^{-1}$ with $1.2 \times 10^{-3} \mathrm{~mol} \mathrm{dm}^{-3} \mathrm{OH}_{2}^{-}$ions as shown in Fig. $1 \& 2$. Acceleration of the rate constants are more than three times in case of the reactions with $\mathrm{OH}_{2}{ }^{-}$ions indicates that $\mathrm{OH}_{2}{ }^{-}$is slightly better nucleophile then $\mathrm{OH}^{-}$. It may be envisaged that probably reacts in competition with $\mathrm{OH}^{-}$in direct nucleophilic attack at phosphorus centre of ester molecule.

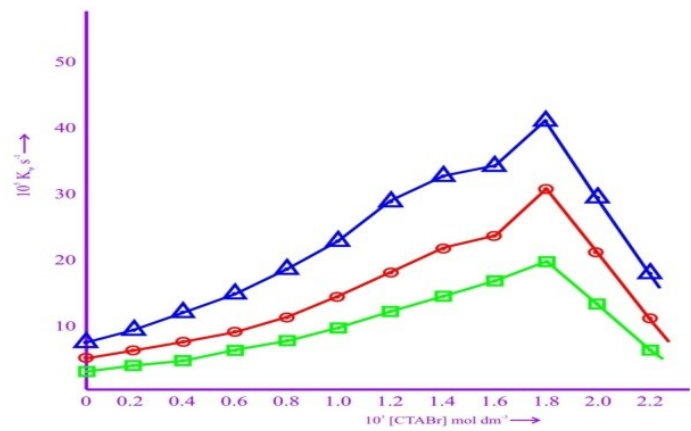

Fig. 1. Reaction of 4-CDMPP with $\mathrm{OH}^{-}$ions in presence and absence of $\mathrm{CTABr}$ at $40 \pm 0.5^{\circ} \mathrm{C}$.
D - $43.8 \times 10^{-3} \mathrm{~mol} \mathrm{dm}^{-3} \mathrm{OH}^{-}$at $\mathrm{pH} 10$,
○ $-20.8 \times 10^{-3} \mathrm{~mol} \mathrm{dm}^{-3} \mathrm{OH}^{-}$at $\mathrm{pH} 9$,

- $\quad-3.9 \times 10^{-3} \mathrm{~mol} \mathrm{dm}^{-3} \mathrm{OH}^{-}$at $\mathrm{pH} 8$ 


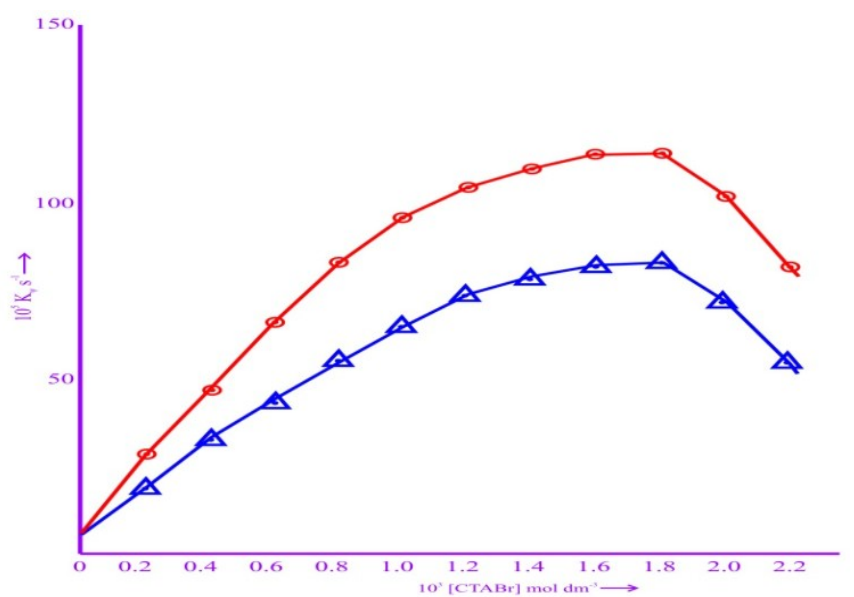

Fig. 2. Reaction of bis-4-CDMPP with $\mathrm{H}_{2} \mathrm{O}_{2}$ in presence of CTABr.
$\Delta-0.8 \times 10^{-3} \mathrm{~mol} \mathrm{dm}^{-3} \mathrm{OH}_{2}{ }^{-}$at $\mathrm{pH} 9$,
○ $-1.2 \times 10^{-3} \mathrm{~mol} \mathrm{dm}^{-3} \mathrm{OH}_{2}{ }^{-}$at $\mathrm{pH} 9$,

From the results presented in Tables 1 and 2, it is evident that maximum rate enhancement occurs in the region of $[\mathrm{CTABr}]$ at which bulk of substrate is incorporated into the micelle. The region for relatively greater enhancement may also be envisaged as due to the hydrogen bonding ${ }^{11}$ between $\mathrm{OH}_{2}{ }^{-}$and $\mathrm{P}-\mathrm{O}$ group of ester. The observed rate enhancement can be explained by considering direct involvement of $\mathrm{OH}_{2}{ }^{-}$in nucleophilic attack on phosphorous atom as shown in above scheme.

\section{Conclusion}

Micellar catalysis has a great potential to explore the condition for enzymatic reactions and collection of data is useful for the development of industries such as leather processing, dye technology, photographic emulsions and pharmaceutical formulations.

\section{References}

[1] C.A. Bunton, L. Robinson, and L. Sepulveda, Journal of organic chemistry, 35, 108, 1970.

[2] A.V. Begunov and C.V. Rutkovskil, Journal of organic chemistry, 42, 2865, 1977.

[3] C.A. Bunton, Ihara Vasuji, Journal of organic chemistry, (USSR), 1607, 16 (8), 1980.

[4] C.A. Bunton, M.M. Mhala, J.R. Maffatt, D. Monarres, and Saveli G., Journal of organic chemistry,49, 426, 1984.

[5] K. Laidler, Journal of Chemical Kinetics (Tata McGraw Hill, New Delhi), 229-230,1965.

[6] E.J. Fendlar, J.H. Fendler, Advanced Physical and Organic Chemistry, 8, 2711970.

[7] P. Brigl, and M. Mullear, Chem. Ber., 728, 2121, 1939.

[8] C.A. Bunton, G. Cerichelli, Y. Ihara, and L. Sepulveda, Journal of American Chemical Society, 101, $2429,1979$.

[9] C.A. Bunton, and L. Robinson, Journal of American Chemical Society, 90, 5972, 1968.

[10] I. Vogel, Elementary Practical Organic Chemistry, Part-2, (Longmans Green and Co., New York).

[11] R.K. Danikhel, and Purnanand, Indian Journal Of Chemistry, 29A, 856-859, 1990. 